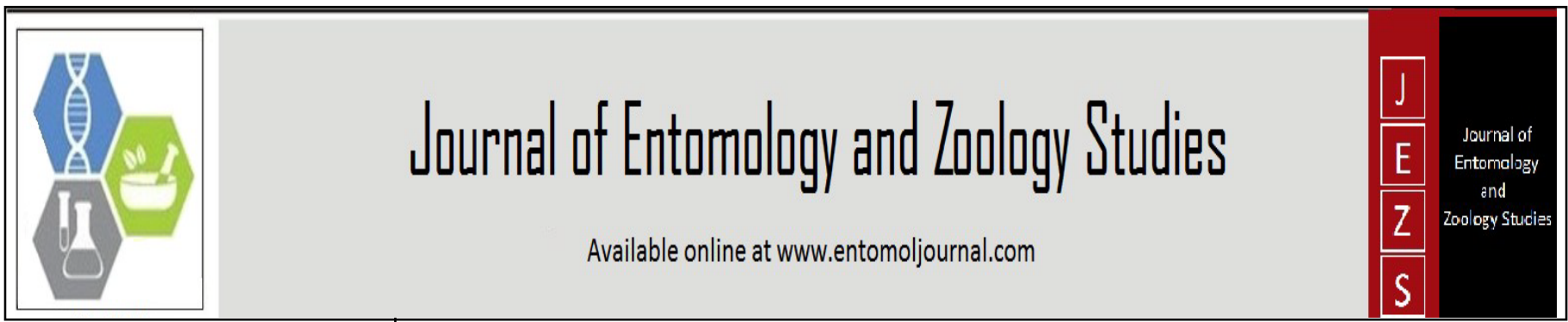

E-ISSN: 2320-7078

P-ISSN: 2349-6800

www.entomoljournal.com JEZS 2021; 9(5): 246-252 (C) $2021 \mathrm{JEZS}$

Received: 25-07-2021

Accepted: 27-08-2021

Arshdeep Singh

Department of Agronomy,

M S Swaminathan School of

Agriculture, Shoolini University,

Solan, Himachal Pradesh, India

Shimpy Sarkar

Department of Entomology,

School of Agriculture, Lovely

Professional University,

Phagwara, Punjab, India
Corresponding Author: Shimpy Sarkar

Department of Entomology,

School of Agriculture, Lovely

Professional University,

Phagwara, Punjab, India

\section{Effect of excess use of fertilizers on insect/pest infestation in Oryza sativa: A review}

\author{
Arshdeep Singh and Shimpy Sarkar
}

DOI: https://doi.org/10.22271/j.ento.2021.v9.i5c.8834

\begin{abstract}
Fertilizer is the most important component for every crop. Specially nitrogen fertilizer plays a vital role for crop production. With maximum use of fertilizers farmers get good result even in same crop varieties and soil. According to the study farmers are believing that if we apply more fertilizer then there will be maximum production. Due to more fertilizer doses the plant tissues are more succulent and can be easily digested by insects. So, most of the insect pests are attracted towards rice crop. There is major three fertilizers which are helping plants for completing their life cycle. These are Nitrogen, which comes from urea application, Phosphorus received from DAP, SSP, TSP and Potassium from Muriate of potash. Nitrogen provides green leafy parts due to carbon element and increase leaf area index which helps in better Photosynthetic rate. Phosphorus is helping in better root growth and establishment and in flower setting or emergence, potassium provides strength to plant for making resistance against of insect/pests' infestation. The doses of NPK are always recommended but according to different studies it has been reported that excess number of fertilizers are majorly responsible for causing disturbance in the balance ratio of plant's metabolism. It was also reported that by increasing nitrogen dose the yield is increased but insect/pest attack is also increased. In this case application of potassium and $\mathrm{ZnSO}_{4}$ is also required to control them in different crops. Anhydrous ammonia also contains nitrogen up to $82 \%$, which is reported as highest, but it is not that much recommended for all crops due to its toxicity level. Due to its highest ammonia, it is recommended that it should be applied at once in the soil by injection or below from the root zone depth of any crop. It was reported that plant hight was good but plant colour, no. of tillers, no. of effective tillers all is less from normal urea fertilizers.
\end{abstract}

Keywords: nitrogen, phosphorus, potassium, insect, infestation, crops, anhydrous ammonia

\section{Introduction}

India alone contributes to $70 \%$ rice production and rest is produced by Pakistan according to world data. According to survey in India the major rice growing states are Uttar Pradesh, Punjab, Haryana, Jammu, and Kashmir. After attaining the level of Basmati by Pusa 1121 in 2008 due to its extra-long grains, good cooking and eating quality and strong aroma, life cycle of 137 days and yield of 13.7 q/ acre, it exceeds its export limits. In 2013-14 Iran contributed $38 \%$ in export of India's Basmati (Sidhu, J.S et al., 2014) ${ }^{[22]}$. In fact, Punjab is not a rice producing state but now a days rice is the main Kharif crop of the state, the north- east part of Punjab (7.25 lakh acres) is under cultivation of Paddy (Kaur, $\mathrm{N}$ et al., 2016) ${ }^{[15]}$. The yield and production were 6q/acre and 43.5 lakh quintals but in comparison to 2013-14, the area, yield and production were 71 lakh quintal, 24q/acre and 1700 lakh quintals. Like this, there is increase in production from 4-40 times in last 50 years due to this change, Punjab is known as rice bowl of India. The area and production in Punjab in 2014-15 were 8.62 lakh hectares, 25.30 lakh tonne, respectively. Urea is basic and important source of nitrogen element with highest nitrogen content $46 \%$ in crystalline form. But anhydrous ammonia carrying $82 \%$ nitrogen content in liquid form, was reported as highest itself. It is recommended that urea fertilizer should be applied in split doses only to avoid its overuse, leaching and volatilisation. Its overuse also affects urease enzyme which is very much important for the crop growth and well establishment. India always imports heavy amount of urea fertilizer from another countries which is an expensive affair. 


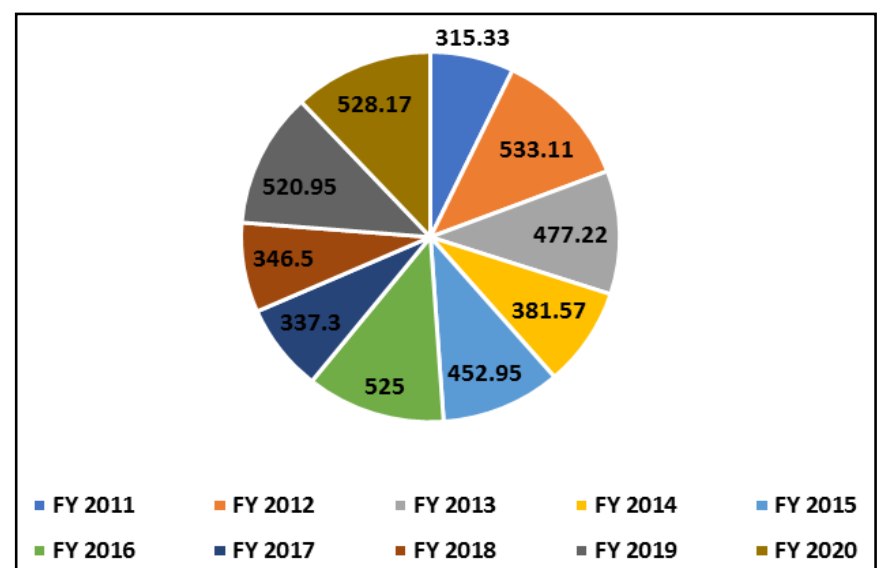

Source: https://www.statista.com/statistics/625203/import-value-offertilizer-india/

Fig 1: Important fertilizers in India from financial years 2011 to 2019 and with estimation of 2020 year in billion India rupees

In the given chart it has been reported that India imported so many numbers of fertilizers to fulfil the requirement with high price. Billions of rupees spent just to import the fertilizers, but the production is not up to the mark. The highest production was recorded during first green revolution in 1960-1965 but after that there is no second green revolution reported till date with using same fertilizers. In 1960's new hybrid seed has been imported with fertilizers. Which shows great results in agriculture sector as most of the soil was unused/uncultivated and had deficiency of nutrients which was completed by using modified inorganic fertilizers. But in another case organic fertilizers also provide organic nutrients. To complete the requirement of crops, it requires in bulk amount but the nutrients releasing process is too slow as compared to inorganic fertilizers. With these reasons the Indian farmer's mentality has been set that with maximum dose of fertilizers, yield will also increase (Singh, A., et al., 2018) ${ }^{[24]}$. But the excess number of fertilizers are always showing bad impact on the crops as well as on soil. Due to more fertilizer insect/pest attack increased and soil became toxic in nature which is harming the root growth. Roots are the major part which is absorbing nutrient from soil as well as soil air and water. But the absorption ratio of root decreases with $\mathrm{pH}$ disturbance. In another case anhydrous ammonia also carries highest ammonia content up to $82 \%$, but this is not recommended for any crop due to its toxicity. The liquid anhydrous ammonia is inserted in soil by injection at once in soil before any crop plantation. In the maize plant it has been reported that where more nitrogen content is present Asian corn borer lay more eggs on its leaves. (Sarajlić, A., et al., 2020) ${ }^{[19]}$.

\section{Effect of excessive use of fertilizers on insect/pest infestation}

Rice is most important crop in worldwide and known as staple food. The $40 \%$ of world's population is dependent on the rice only due to its high nutritional value for daily diet. According to the study farmers are believing that if we apply more fertilizer then there will be maximum production. Due to more fertilizer doses the plant tissues are more succulent and easily digested. So, most the insect pest is attracted toward rice and other crops.

There are some studies related to this article

The Green Revolution was one of the best events in agricultural history. Because, before that there was food scarcity in all over the world due to the increasing rate of population, but after green revolution the face of agriculture was totally changed, and good production was achieved. This process can never touch the satisfaction level. Greenrevolution has been successful with the new breeder seeds and fertilizers. Specially the combination of nitrogen and phosphorous fertilizers. Nitrogen is more responsible for vegetative growth of crops and phosphorous is required for better root growth. So, that more nutrients should be absorbed by the root hairs. New hybrid varieties showed great response towards fertilizers application and being able to achieve double production of grains like rice, wheat, and maize. Due to the application of excessive fertilizers, pesticides with all positive aspects there are some negative aspects also like disturbance in crop canopy conditions and there is big disturbance in animal and plant communities (Conway, G., 2019 and Conway, G.R. and Pretty, J.N., 2013) ${ }^{[5,6]}$. Insects/pests are responsible for huge loss of crops. To stop their activity, farmers apply more pesticides which are very much toxic in nature and have long time residual activity in grains (Scriber, J.M., 1984) ${ }^{[20]}$.

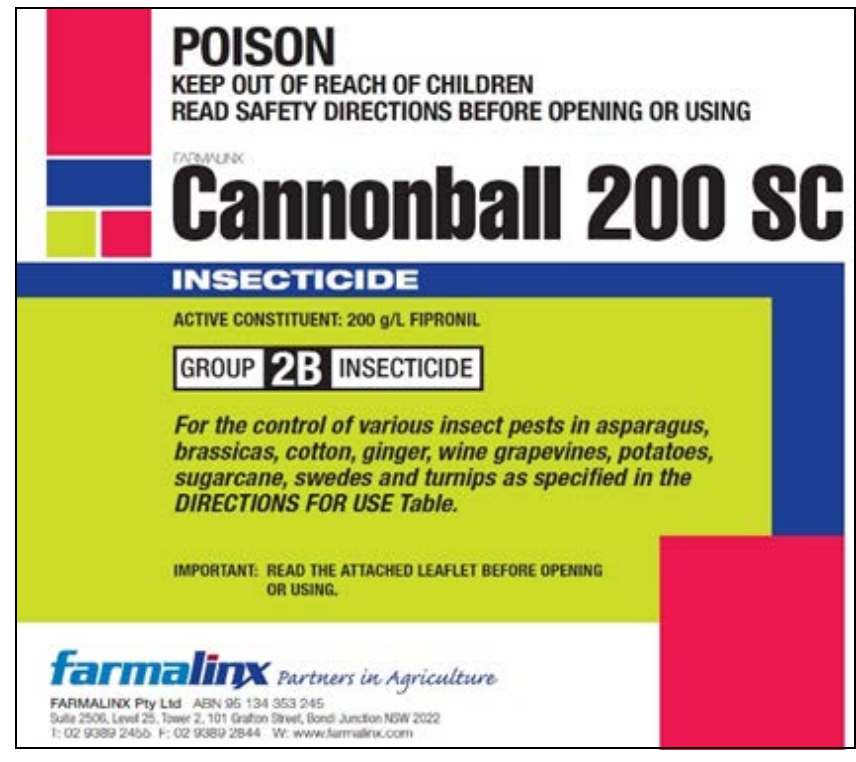

http://agrilife.org/citybugstest/files/2010/06/Pesticide-label2.jpg

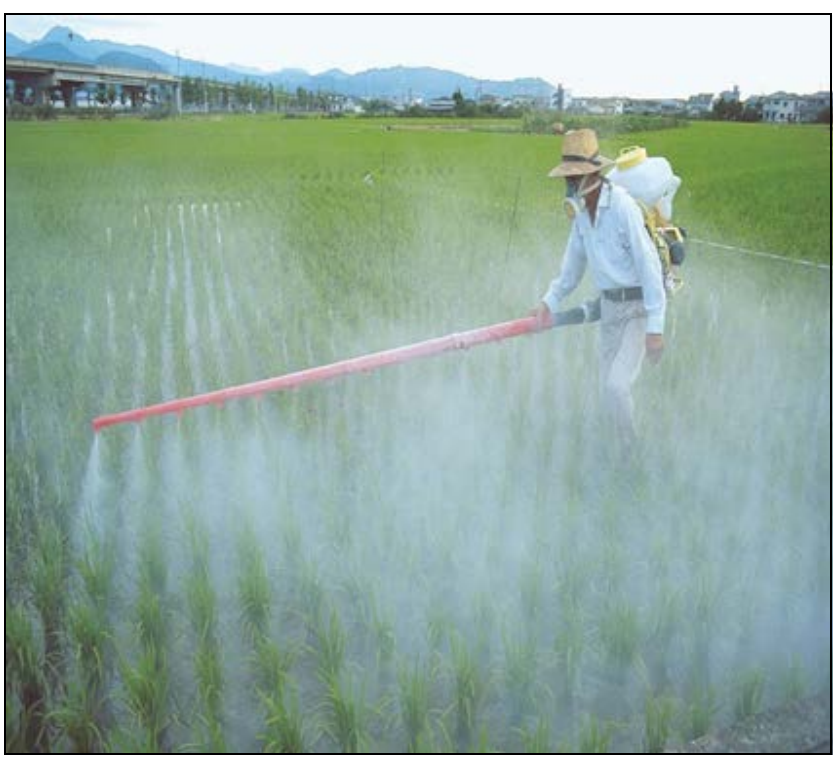

https://www.britannica.com/technology/insecticide 
Rice is a staple food from long time in Asia. Almost everyone has experience with the rice or its product at once in their life due to its good carbohydrates and energy. But it has been also reported that, yellow stem borer, leaf folder, green leaf hopper and brown plant hopper causes heavy loss in rice production from 3-65\% by yellow stem borer (Ghose, R.L.M., et al., 1960) ${ }^{[8]}$ and 5-25\% by leaf folder only (Edwin Binjhan Copeland, 1924) ${ }^{[7]}$. There are so many constraints of rice crop production caused by the infestation of insects and pests. So, regular care and attention is required. On the large-scale rice production recorded in millions of tonnes but there is also chance of yield loss due to insects and pests by using dense plant population, water regime, hybrid varieties, excess use of fertilizers etc.

Due to all this, prevention, control, and management of insect/pests is very important. Pesticides are very harmful as they possess residual effect. So, cultural method always show good results without any harmful effects. The sowing time of the rice crop can be changed for reducing the attack of insect/pest. But the incidence of plant hoppers, yellow stem borer, leaf folder and brown plant hopper's attack recorded less where more amount of potash has been applied in the field as comparison to nitrogenous fertilizers because nitrogen fertilizer enhances the plant growth and make the plant leaf more succulent which is easy to digest for insects/pests (Pramanick, M et al., 1995) ${ }^{[17]}$. Especially leaf folder attack was recorded high with high doses of nitrogen fertilizer (Subbaih and Morachan 1974) ${ }^{[25]}$. But with the high dose of potassium leaf folder attack can be reduced (Raju et al., 1996) [18]. Potassium works as a resistance against the leaf folder insects. There are so many losses recorded, like more input of fertilizers which are very costly without subsidies, reduction in yield, increase in insect/pest attack, resistivity in insects and pest against many insecticides and pesticides but some of the pesticide and insecticides are extremely toxic in nature and have long residual effect in soil, grains, and plants. The calculation of insects/pest's attack on rice crop is particularly important so that pest population can be bring down below the threshold level, by using the following formula.

\section{Percent damaged leaves $=\frac{\text { Number of damaged leaves }}{\text { Total number of leaves }} \times 100$}

On the leaves number of dead hearts/white ears and the percent incidence (dead heart/white ears) of yellow stem borer is calculated as follows.

\section{Percent incidence $=\frac{\text { Number of dead heart/ white ears }}{\text { Total }} \times 100$ \\ Total number of tillers/panicles}

Total 10 panicles are required to take the proper reading. The percent damaged grain is calculated as follows.

Percent grain damaged $=\frac{\text { Number of damaged grains }}{\text { Total number of grains }} \times 100$

Reason behind more insect/pest attack on crops- Urea is one of the major sources of nitrogen element for crops. Excessive amount of urea produces more succulent vegetative parts. Which have darker green in color and as a result attracts more insects like, BPH, Grasshopper and leaf folder (Caldirola, P., 1995) ${ }^{[4]}$.

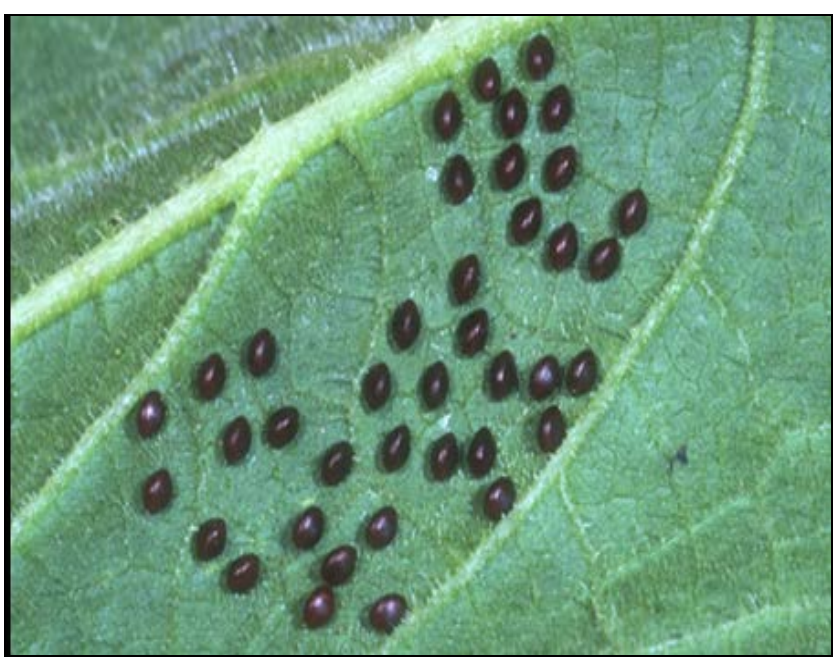

http://magickcanoe.com/insects/egg-laying-1.jpg

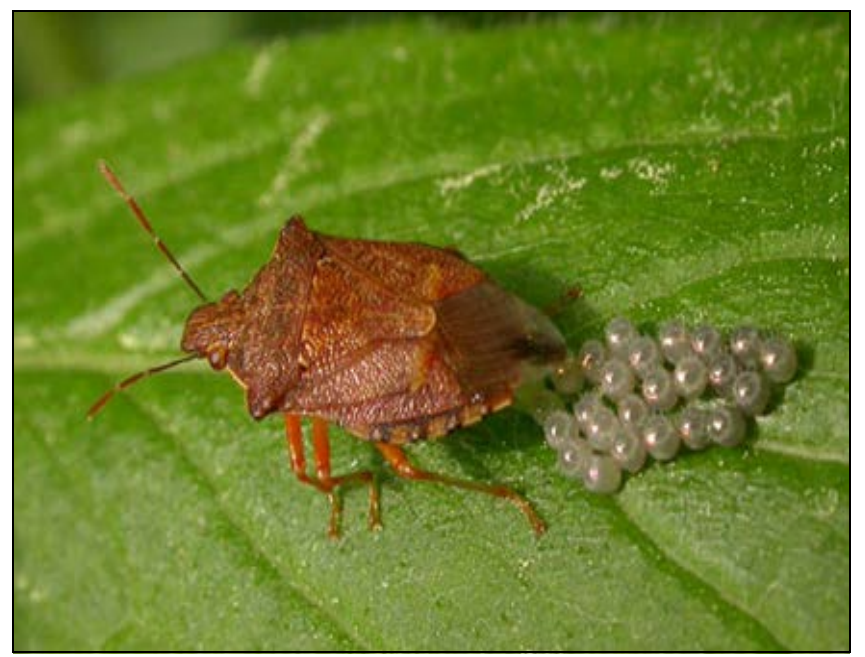

Cluster of squash bug eggs Photograph by John L. Capinera,

Selection of host plant by insects: Insect always select their host plant where more fertilizers has been applied due to increase in their survival ratio (Bernays, E.A., 2019 and Simpson, S.J. and Raubenheimer, D., 1993) ${ }^{[23,3]}$. Nitrogen always enhances the nutritional value of plants and the behavioural activity of the insects (Barbour, J.D., 1991) ${ }^{[1]}$. In the host plant generally amount of nitrogen fertilizer dose was recorded high as compared to other plant from same land and this is the only reason behind the selection of host plant (Bentz, J.A., et al., 1995) ${ }^{[2]}$. In the maize plant it has been reported that where more nitrogen content was present, Asian corn borer laid more eggs on the maize plant leaves (Bentz, J.A., et al., 1995) ${ }^{[2]}$.

Life cycle of insects: Insects have many growth stages in their life cycle like egg, larva, pupa, and adult stage. According to their life stages chemical should be applied, so that they can be killed with the right dose, at right time with minimum effects. There are so many insects present which are harmful to rice crop like yellow stem borer, green leaf hopper, brown plant hopper and leaf folder etc. which causes heavy losses in rice crop by damaging their leaf, stem, panicles etc.

\section{Insecticide and pesticides application for different insects}

1. Yellow stem borer: There are so many insecticides available in the market to kill the yellow stem borer but Flubendiamide 20\% WG @ 25g a.i/ha was found one of 
the best effective treatment against the rice yellow stem borer insect (Shyamrao, I.D. and Raghuraman, M., 2019) [21]. The infestation of yellow stem borer varied in between 3.85 to 7.85 percent but with the application of Flubendiamide 20\% WG @ 25g a.i/ha its infestation reduced.

2. Green leaf hopper: Green leaf hopper is very harmful for rice crop because it is also responsible to spread the rice tungro virus disease which causes heavy loss in rice crop production, to kill the green leaf hopper six insecticides are available viz., cypermethrin, detamethrin, ethofenprox, triazophos, fenobucarb and metolcarb), which can reduce the infestation of green leaf hopper up to 75 to 100 percent within 48 hours after its application. Insecticide like cypermethrin, detamethrin and ethofenprox is very much effective against the adult and nymphal population. With the application of cypermethrin virus infection is also reduced up to 10 percent within 60 days after application (Macatula, R.F et al., 1987) ${ }^{[16]}$.

3. Brown plant hopper: Brown plant hopper is very much common in rice crop as a major pest. It damages rice leaves by sucking the cell sap, after that leaves turn into yellow colour from green colour. After turning into yellow colour further leaf colour turn into brown colour patches and that type of affected field is known as hopper burn in rice. The infestation of brown plant hopper always increases with high atmospheric humidity, good and optimum temperature for its growth and majorly high dose of nitrogen fertilizer in rice crop. For controlling brown plant hopper, taking care of the rice plants is particularly important just after transplantation. Use insecticide such as Chess, which is very much effective against the brown plant hopper, when it cannot be controlled by natural methods. Chess effect will be present for long time in the plants to control the infestation of brown plant hopper and rice yield can be increased under the proper controlled conditions (www.syngenta.co.in).

4. Leaf folder: Leaf folder insect is also quite common like brown plant hopper in rice crop, and it can be found in rice field at any stages, but its favourite stage is tillering stages because tillering stage is known as growing stage and mostly the leaves are soft in nature and can be easily curled. If more leaves are curled during the tillering stage, maximum yield will be reduced. Leaf folder in its caterpillar/larval stage can role the leaf around their body with saliva and feed inside the tube. For its control apply alpha-cypermethrin, abamectin 2 percent to kill the leaf folder at larvae stage (www.plantwise.org).

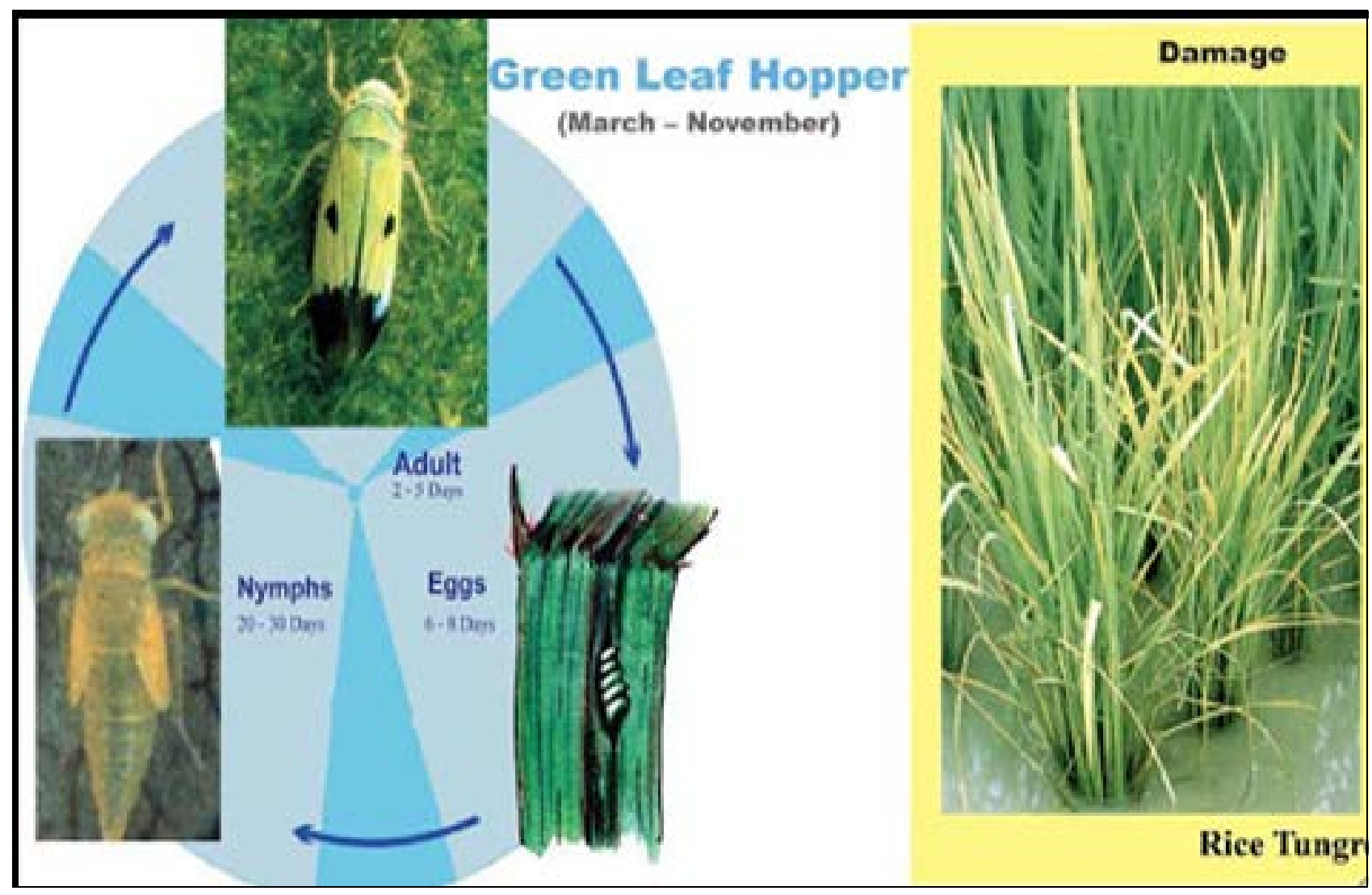

Life cycle of yellow stem borer 


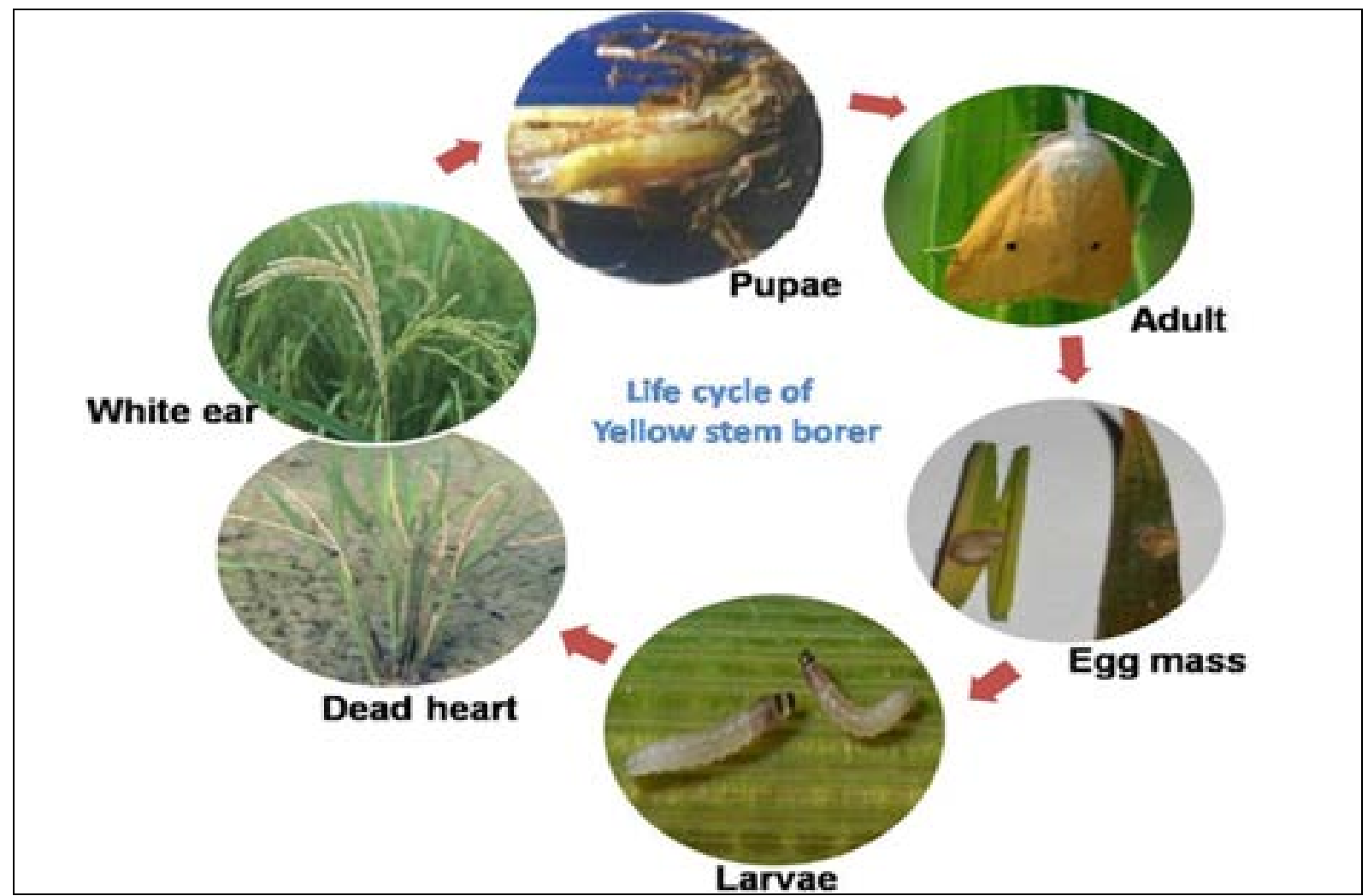

Life cycle of green leaf hopper

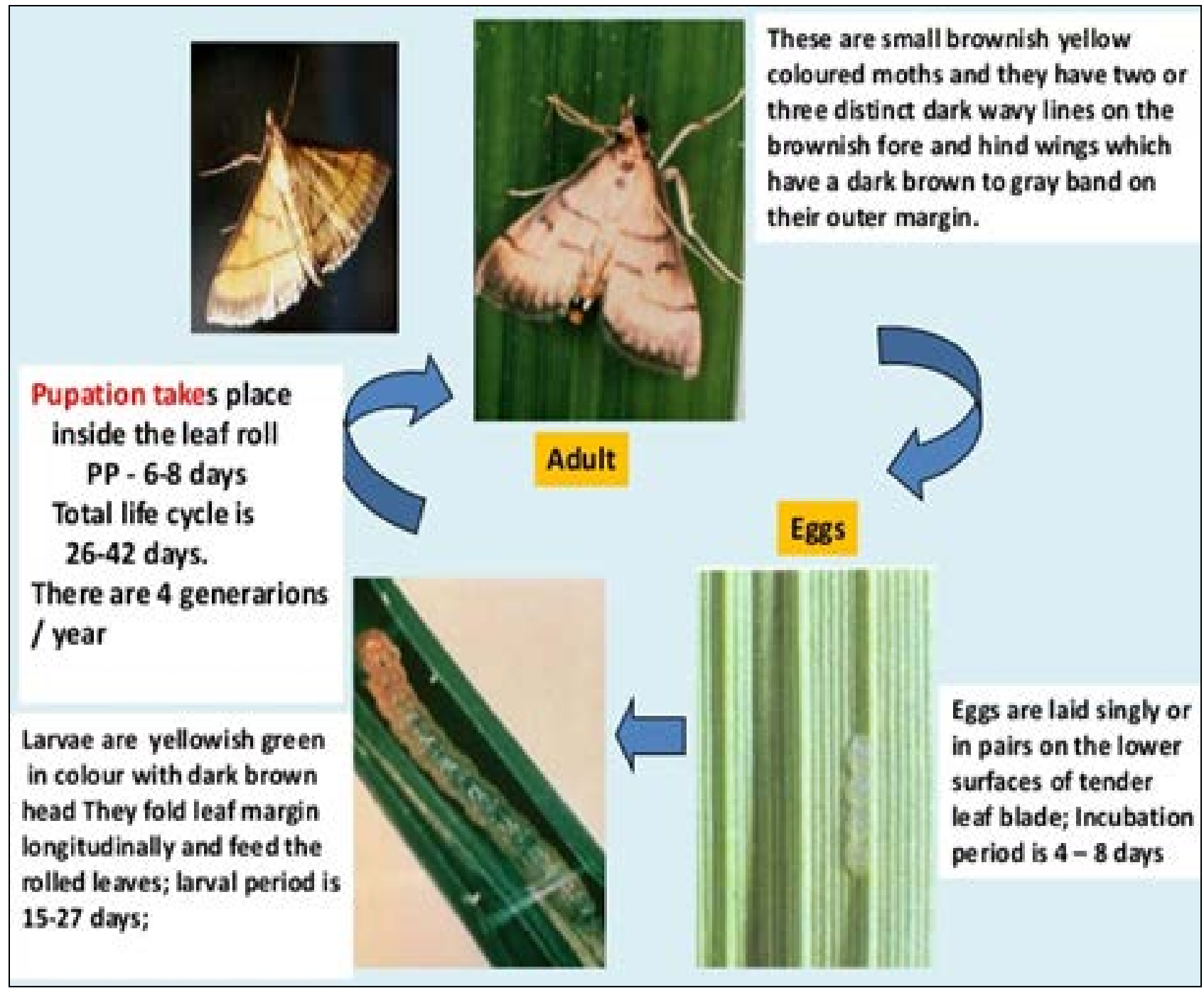




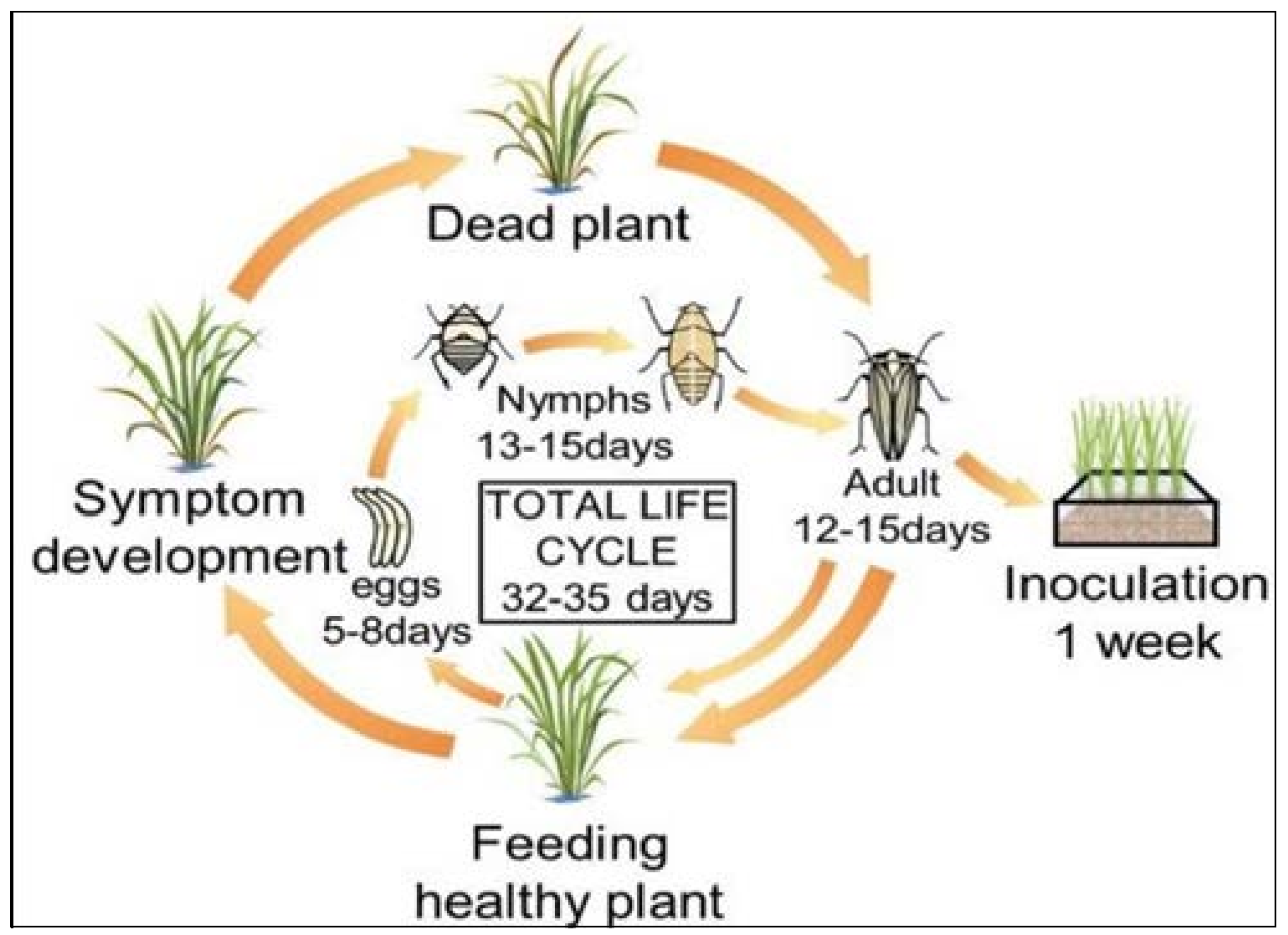

Life cycle of leaf folder

\section{Conclusion}

The excess use of fertilizers always cause problem for crops and it is an invitation for insect/pests. By using a greater number of fertilizers, the plant cells become more succulent and easily digestible by the insects. The application of zinc fertilizer is helpful to repel the insects due to bitterness in the leaves. Similarly, some other IPM tactics and tools must be included starting from the land preparation stage of the crop to reduce the inoculum or entry of insect/pest in any crop. In rice, we can follow the IPM tools to maintain the major insect/pest population below ETL, which is particularly important for a better yield. Continuous exposure to chemical alternatives is only deteriorating the health of soil and environment, also causing a lot of expenditure for fertilizer and other such inputs. The knowledge gap should be tried to minimize for better future of crops which is only possible by proper communication and dissemination of information.

\section{References}

1. Barbour JD, Farrar Jr RR, Kennedy GG. Interaction of fertilizer regime with host-plant resistance in tomato. Entomologia Experimentalis et Applicata 1991;60(3):289-300.

2. Bentz JA, Reeves J, Barbosa P, Francis B. Within-plant variation in nitrogen and sugar content of poinsettia and its effects on the oviposition pattern, survival, and development of Bemisia argentifolii (Homoptera: Aleyrodidae). Environmental entomology (USA) 1995.

3. Bernays EA. An unlikely beginning: a fortunate life. Annual review of entomology 2019;64:1-13.

4. Caldirola P. Southwood, TRE-Ecological Methods, with Particular Reference to the Study of Insect Populations 1968.

5. Conway G. The doubly green revolution: food for all in the twenty-first century. Cornell University Press 2019.

6. Conway GR, Pretty JN. Unwelcome harvest: agriculture and pollution. Routledge 2013.

7. Edwin Bingham Copeland, Rice, Macmillan and Co. Ltd. London 2013, 351

8. Ghoze RLM, Ghatge MB, Subramamanyan V. Rice in India (revised edition). New Delhi, India, Indian Council of Agricultural Research 1960.

9. http://agrilife.org/citybugstest/files/2010/06/Pesticidelabel2.jpg

10. http://magickcanoe.com/insects/egg-laying-1.jpg

11. https://www.britannica.com/technology/insecticide

12. https://www.plantwise.org/KnowledgeBank/factsheetforf armers/20147800010\#: :text=Rice\%20leaf\%20folder\%2 0is\%20a,on\%20weeds\%20around\%20the\%20bunds.

13. https://www.statista.com/statistics/625203/import-valueof-fertilizer-india/

14. https://www.syngenta.co.in/high-quality-rice crop\#: :text=Chess\%20is\%20the\%20most\%20effective, which\%20will\%20generate\%20higher\%20yield.

15. Kaur N, Singh J, Kumar S. Comparative Economic Analysis of Basmati and Non-Basmati Paddy Cultivation in Punjab. Indian Journal of Economics and Development 2016;12(3):439-444.

16. Macatula RF, Valencia SL, Mochida O. Evaluation of 12 insecticides against green leafhopper for preventing rice tungro virus disease. Evaluation of 12 insecticides against green leafhopper for preventing rice tungro virus disease. 1987, 128.

17. Pramanick M, Des M, Ghosh MR, Mukherjee N. Effect of fertilizer treatments on growth, productivity, insectpest and disease incidences on rice. Madras agricultural Journal 1995;82:525-527.

18. Raju N, Nagarajan R, Rajendran KA, Kareem A. Role of 
nitrogen $(\mathrm{N})$ and potassium $(\mathrm{K})$ in the incidence of green leafhopper (GLH) Nephotettix virescence (Distant) in Rice. J Potassium Res 1996;12(3):313-318.

19. Sarajlić A, Raspudić E, Lončarić Z, Josipović M, Majić I. The Role of Irrigation and Nitrogen Fertilization on the Feeding Behavior of European Corn Borer. In Pests, Weeds and Diseases in Agricultural Crop and Animal Husbandry Production. Intech Open 2020.

20. Scriber JM. Nitrogen nutrition of plants and insect invasion. Nitrogen in crop production, 1984, 441-460.

21. Shyamrao ID, Raghuraman M. Bio-efficacy of insecticides against yellow stem borer (Scirpophaga incertulas Walker) in rice (O. sativa L.) ecosystem of Varanasi region. Journal of Pharmacognosy and Phytochemistry 2019;8(2):301-304.

22. Sidhu JS, Singh J, Kumar R. Role of market intelligence in agriculture: A success story of basmati cultivation in Punjab. Indian Journal of Economics and Development 2014;10(1a):26-31.

23. Simpson SJ, Raubenheimer D. The central role of the haemolymph in the regulation of nutrient intake in insects. Physiological Entomology 1993;18(4):395-403.

24. Singh A, Kumar A, Jaswal A, Singh M, Gaikwad D. Nutrient use efficiency concept and interventions for improving nitrogen use efficiency. Plant Archives 2018;18(1):1015-1023.

25. Subbiah KK, Morachan YB. Effect of nitrogen nutrition and rice varieties on the incidence of leaf roller (Cnaphalocrocis medinalis Guen.). Madras agric. J 1974;61:716. 